\title{
Numerical Study of Methane Dry Reforming Reaction in a Disk Reactor with Focused Solar Simulator
}

\author{
Yarong Wang1, Jing Ding2, Jianfeng Lu ${ }^{2 *}$ \\ ${ }^{1}$ School of Intelligent Systems Engineering, Sun Yat-sen University, Guangzhou, China \\ ${ }^{2}$ School of Materials and Engineering, Sun Yat-sen University, Guangzhou, China \\ Email: ^lujfeng@mail.sysu.edu.cn
}

How to cite this paper: Wang, Y.R., Ding, J. and Lu, J.F. (2020) Numerical Study of Methane Dry Reforming Reaction in a Disk Reactor with Focused Solar Simulator. Energy and Power Engineering, 12, 59-72. https://doi.org/10.4236/epe.2020.122005

Received: January 16, 2020

Accepted: February 14, 2020

Published: February 17, 2020

Copyright $\odot 2020$ by author(s) and Scientific Research Publishing Inc. This work is licensed under the Creative Commons Attribution International License (CC BY 4.0).

http://creativecommons.org/licenses/by/4.0/ (c) (i) Open Access

\begin{abstract}
Heat transfer and thermochemical energy storage process of methane dry reforming in a disk reactor with focused solar simulator was modeled and analyzed. The results showed that thermochemical energy storage efficiency of disk reactor can reach $28.4 \%$, and that is higher than that of tubular reactor. The maximum reaction rate occurs at catalyst bed corner near the baffle, because the corner has high temperature and high reactant molar fraction. As reactant flow increases, methane conversion and thermochemical energy storage efficiency decrease as catalyst bed temperature and heat loss decrease. The thermochemical energy storage efficiency increased first and then decreased with methane molar ratio increasing, while methane conversion and the thermochemical energy storage efficiency increased with reactant temperature increasing. As catalyst bed porosity rises, methane conversion and thermochemical energy storage efficiency increased first and then decreased, and optimum porosity is 0.31 .
\end{abstract}

\section{Keywords}

Methane Dry Reforming, Thermochemical Energy Storage, Focused Solar Simulator, Disk Reactor

\section{Introduction}

Solar energy is a kind of abundant clean energy, but the cost of energy development and utilization is high and the efficiency is low due to its dispersion and instability. Thermochemical energy storage technology is the most promising high-temperature energy storage method. Research in the past two decades has 
shown that solar thermal energy can effectively drive chemical conversion reactions [1] [2]. Methane dry reforming thermochemical energy storage is a form of efficient energy utilization that can convert solar energy into stable chemical combustion energy [1]. Its main advantages [2] include large storage capacity per unit of methane, high temperature reaction condition $\left(>600^{\circ} \mathrm{C}\right)$, and full use of greenhouse gases $\mathrm{CH}_{4}$ and $\mathrm{CO}_{2}$.

In recent years, solar reforming reactors are mainly developed into three types: indirectly heated reformer, tubular reformer-receiver and the windowed or volumetric reformer-receiver [3]. ASTERIX [4] [5] carried out solar steam reforming experiment of methane in the early 1990s, and studied details and related problems of process heat demand of industrial chemical process with solar energy and high temperature using indirect heating converter. The catalytically enhanced solar absorption receiver (CAESAR) [6] [7] test was used to determine the thermal, chemical, and mechanical properties of a commercial scale dish-shaped direct catalytic absorption receiver reactor under a series of steady-state and transient operating conditions. In order to perform an efficient carbon dioxide and water vapor reforming reaction, Weizmann Institute of Science designed a solar receiver with storage and transportation for high-temperature technology development, and tested it in a $480 \mathrm{~kW}$ reformer [8]. Jin et al. [9] proposed a methane reforming reactor with a compound paraboloid concentrator and a mesh porous ceramic. The simulation results show that compared with the traditional reactor design, the reactor design proposed in this study can improve the photochemical efficiency of solar methane conversion.

In addition to experimental research, the researchers conducted a large number of numerical simulation studies. Rubin et al. [10] proposed a numerical model based on Arrhenius equation for simulating methane steam reforming, and simulation results were in agreement with experimental results. Akpan et al. [11] established a reaction kinetics model for carbon dioxide methane reforming under $\mathrm{Ni} / \mathrm{CeO}_{2}-\mathrm{ZrO}_{2}$ catalyst through experiments and simulations. Akbanri et al. [12] established a three-dimensional microreactor model for simulating methane autothermal reforming in fuel cells, and studied the effects of airspeed, air/fuel ratio, water-fuel ratio and inlet temperature on the reaction. Wang et al. [13] [14] [15] used combined method with Monte Carlo Ray Tracing method and Finite Volume Method to establish heat and mass transfer model coupled with thermochemical reaction kinetics for porous medium solar thermochemical reactor. The numerical results showed that concentrated solar irradiation affects reactor thermal performance, methane steam reforming chemical reaction rate and hydrogen production. Gu et al. [16] analyzed heat transfer and storage performance of steam methane reforming in tubular reactor with focused solar simulator by measurement and simulation. Fernando et al. [17] found that methane steam reforming in a fixed-bed reactor can efficiently store thermal energy in high temperature. Benguerba et al. [18] analyzed the effect of using different 
temperatures on the methane dry reforming performance in a fixed-bed catalytic reactor by a one-dimensional heterogeneous model.

At present, the research on methane dry reforming thermochemical energy storage process in enhanced reactor still need to be further investigated. In this paper, the thermochemical storage performance of methane dry reforming disk reactor was studied with focused solar simulator. The reactant flow, reactant methane molar ratio, reactant temperature and catalyst bed porosity were analyzed for mechanism of methane dry reforming process in the disk reactor, to find a new method to improve the methane conversion and energy storage efficiency of the system.

\section{Numerical Model}

\subsection{Model Introduction}

Figure 1 describes physical model of a methane dry reforming disk reactor with

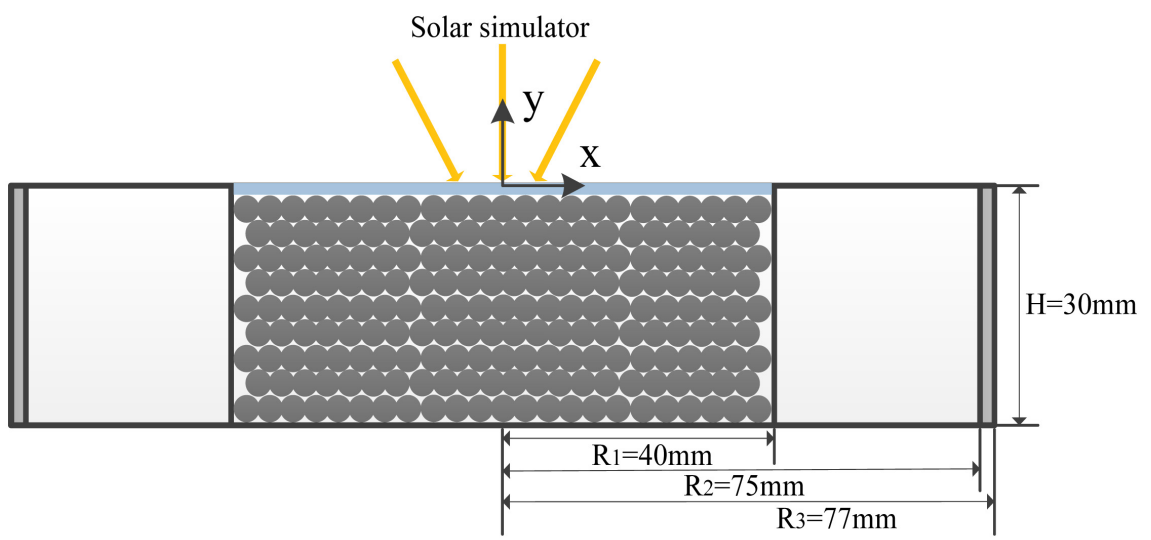

(a)

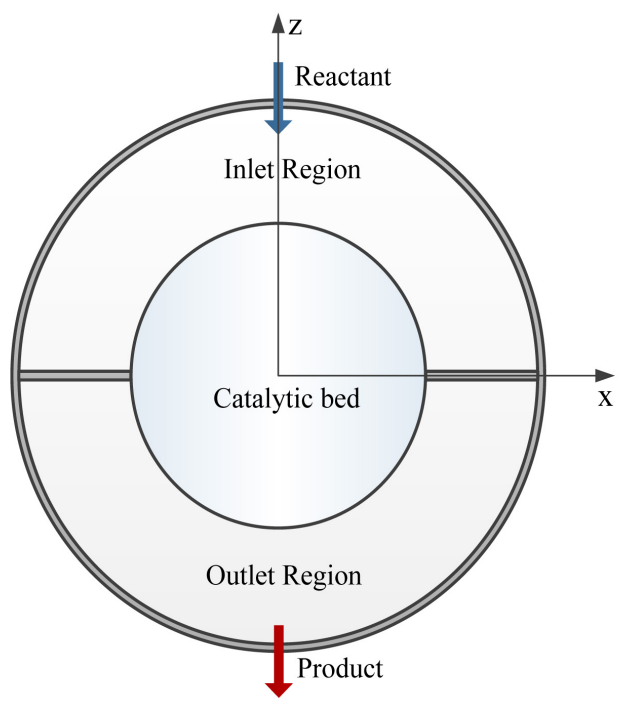

(b)

Figure 1. Physical model of disk reactor with solar simulator. (a) $x=0$ section, (b) $y=0$ section. 
focused solar simulator. The reformer is a disk with radius of $\mathrm{R}_{3}$ and height of $\mathrm{H}$, and catalyst is also a disk with radius of $\mathrm{R}_{1}$. The inlet region and outlet region are separated by catalyst bed and two baffles. The outer surface with quartz glass at $y=0$ is heated by concentrated heat flow from solar simulator.

The main reaction of methane dry reforming reaction is:

$$
\mathrm{CH}_{4}+\mathrm{CO}_{2} \leftrightarrow 2 \mathrm{CO}+2 \mathrm{H}_{2}, \Delta H_{m}=+247.3 \mathrm{~kJ} / \mathrm{mol}
$$

The main side reaction is:

$$
\mathrm{CO}_{2}+\mathrm{H}_{2} \leftrightarrow \mathrm{CO}+\mathrm{H}_{2} \mathrm{O}, \Delta H_{s}=+41.1 \mathrm{~kJ} / \mathrm{mol}
$$

Inlet mole fraction of methane is:

$$
y=\frac{F_{\mathrm{CH}_{4}, i}}{F_{\mathrm{CH}_{4}, i}+F_{\mathrm{CO}_{2}, i}}
$$

where $F_{\mathrm{CH}_{4}, i}$ and $F_{\mathrm{CO}_{2}, i}$ denote inlet flow rates of methane and carbon dioxide under standard condition $\left(1 \mathrm{~atm}, 20^{\circ} \mathrm{C}\right)$, respectively.

Methane conversion is:

$$
X_{\mathrm{CH}_{4}}=\frac{F_{\mathrm{CH}_{4}, i}-F_{\mathrm{CH}_{4}, \mathrm{o}}}{F_{\mathrm{CH}_{4}, i}}
$$

where $F_{\mathrm{CH}_{4}, \mathrm{o}}$ is methane outlet flow under standard condition.

Carbon dioxide conversion rate is:

$$
X_{\mathrm{CO}_{2}}=\frac{F_{\mathrm{CO}_{2}, i}-F_{\mathrm{CO}_{2}, o}}{F_{\mathrm{CO}_{2}, i}}
$$

where $F_{\mathrm{CO}_{2}, \mathrm{o}}$ is carbon dioxide outlet flow under standard condition.

The energy flow received by reactor from solar simulator is:

$$
E_{\text {in }}=\iint_{S_{w}} q_{r} \mathrm{~d} S
$$

where $q_{r}$ is concentrated radiant heat flux on reactor surface, $S_{w}$ is surface area of reactor irradiate by solar simulator.

$$
q_{r}=q_{c} \exp \left(-1464.3 r^{2}\right)
$$

where $q_{c}$ denotes central heat flux, and $r$ denotes radius from focus.

Thermochemical energy storage is:

$$
Q_{c h}=\frac{F_{\mathrm{CH}_{4}} \cdot X_{\mathrm{CH}_{4}} \cdot \Delta H_{m}}{v_{\mathrm{CH}_{4}}}+\frac{F_{\mathrm{CO}_{2}} \cdot\left(X_{\mathrm{CO}_{2}}-X_{\mathrm{CH}_{4}}\right) \cdot \Delta H_{s}}{v_{\mathrm{CO}_{2}}}
$$

where $v$ denote mole volume under standard condition. $\Delta H_{m}$ and $\Delta H_{s}$ are reaction heat of main reaction and side reaction.

Sensible heat increment is [18]:

$$
Q_{s e}=\sum_{i} \int_{T_{s}}^{T_{0}} F_{o, i} \rho_{o, i} C_{p, o, i} \mathrm{~d} T
$$

where $\rho_{o, i}, \quad C_{p, o, i}$ are density and specific heat of species $i$ in product, $T_{s}$ and $T_{0}$ are surrounding and outlet temperatures. 
Thermochemical energy storage efficiency and total energy storage efficiency are:

$$
\begin{gathered}
\eta_{c h}=\frac{Q_{c h}}{E_{\text {in }}} \\
\eta_{\text {total }}=\frac{Q_{\text {total }}}{E_{\text {in }}}=\frac{Q_{c h}+Q_{\text {se }}}{E_{\text {in }}}
\end{gathered}
$$

\subsection{Theoretical Assumption and Model}

Based on existing experimental data, a three-dimensional model of disk reactor with solar simulator is established. The entire process is assumed to be steady, and fluid is assumed to be ideal gas. The model contains solid domain of reactor wall, fluid domain with porous media inside reactor. Catalyst bed is assumed as porous media.

The fluid zone includes inlet and outlet regions, and porous zone of catalyst bed. Continuity equation can be expressed as:

$$
\frac{\partial\left(\rho_{f} u_{i}\right)}{\partial x_{i}}=0
$$

where $\rho_{f}$ is density of mixed fluid, $u_{i}$ is superficial velocity vector based on the total cross-sectional area of fluid and porous medium.

Momentum conservation equation is expressed as:

$$
\frac{\partial}{\partial x_{j}}\left(\rho_{f} u_{i} u_{j}\right)=\frac{\partial}{\partial x_{j}}\left(\mu \frac{\partial u_{i}}{\partial x_{j}}\right)-\frac{\partial p}{\partial x_{i}}+\rho_{f} g_{i}+S_{m, i}
$$

where $\mu$ is dynamic viscosity, $p$ is fluid pressure, $g_{i}$ is gravitational acceleration and $S_{m, i}$ is momentum source caused by flow in porous media. In the inlet and outlet regions, $S_{m, i}=0$.

The momentum source for homogeneous porous media consists of viscosity loss term and inertia term as [19]:

$$
S_{m, i}=\left(\frac{\mu}{\alpha} u_{i}+C_{2} \frac{1}{2} \rho_{f}|u| u_{i}\right)
$$

The permeability and internal resistance factor [20] can be calculated as:

$$
\begin{gathered}
\alpha=\frac{D_{p}^{2}}{150} \frac{\gamma^{3}}{(1-\gamma)^{2}} \\
C_{2}=\frac{3.5}{D_{p}} \frac{1-\gamma}{\gamma^{3}}
\end{gathered}
$$

where $D_{p}$ is the diameter of catalyst particles.

During chemical reaction process, the fractions of reactants and products change, and mass transport equation is [19]:

$$
\frac{\partial}{\partial x_{j}}\left(\rho_{f} Y_{i} u_{j}\right)+\frac{\partial J_{i, j}}{\partial x_{j}}=r_{i}
$$


where $Y_{i}, J_{i, j}$ and $r_{i}$ are respectively mass fraction, diffusion flux and reaction rate for species.

Chemical reaction is assumed as volumetric reaction, and the reaction rate is calculated by standard Arrhenius equation as:

$$
k=A \mathrm{e}^{-E_{a} / R T}
$$

where $A$ and $E_{a}$ mean pre-reaction factor and activation energy.

In solid zone of reactor wall, heat transfer is controlled by heat conduction, and its governing equation is:

$$
\frac{\partial}{\partial x_{i}}\left(k_{w} \frac{\partial T_{w}}{\partial x_{i}}\right)=0
$$

where $T_{w}$ is temperature of reactor wall, and $k_{w}$ is the thermal conductivity.

In fluid zone, energy conservation equation can be expressed as:

$$
\frac{\partial}{\partial x_{i}}\left(\rho_{f} c_{p} u_{i} T\right)=\frac{\partial}{\partial x_{i}}\left(k_{e f f} \frac{\partial T}{\partial x_{i}}\right)+S_{h}
$$

where $S_{h}$ is energy source caused by chemical reaction, and $k_{\text {eff }}$ is effective conductivity. $S_{h}$ is directly calculated by enthalpy difference of reactants and products.

The effective thermal conductivity is calculated as volume average of thermal conductivities of fluid and solid as [21]:

$$
k_{e f f}=\gamma k_{f}+(1-\gamma) k_{s}
$$

where $k_{f}$ and $k_{s}$ are conductivity of fluid and porous medium, respectively.

The heat loss from the reactor wall is primarily determined by natural convection and radiation. The boundary condition for heating surface is:

$$
-k_{w} \nabla T_{w}=h_{n}\left(T_{w}-T_{s}\right)+\varepsilon \sigma\left(T_{w}^{4}-T_{s}^{4}\right)-q_{r}
$$

where $h_{n}$ is heat transfer coefficient of natural convection, $\sigma$ is black body radiation constant, $\varepsilon$ is emissivity, and $T_{s}$ is surrounding temperature.

The boundary condition of back surface is:

$$
-k_{w} \nabla T_{w}=h_{n}\left(T_{w}-T_{s}\right)+\varepsilon \sigma\left(T_{w}^{4}-T_{s}^{4}\right)
$$

\subsection{Calculation Condition and Model Validation}

According to the experimental results, the pre-exponential factor and activation energy of the main reaction are $A_{1}=1.2 \times 10^{7}$ and $E a_{1}=5.8 \times 10^{7} \mathrm{~J} / \mathrm{kmol}$, and those of side reaction are $A_{2}=31900$ and $E a_{2}=1.69 \times 10^{7} \mathrm{~J} / \mathrm{kmol}$. The heating surface of the reactor is affected by the air-cooling system, and $h_{h}=12.6 \mathrm{~W} / \mathrm{m}^{2} \cdot \mathrm{K}$, while convective heat transfer coefficient on back side is $h_{h}=4 \mathrm{~W} / \mathrm{m}^{2} \cdot \mathrm{K}$. The emissivity $\varepsilon$ of the outer wall surface of the reactor is 0.93 , the ambient temperature was $25^{\circ} \mathrm{C}$, and the flow of the reactant inlet was uniform.

Yu et al. [22] experimentally measured tubular methane dry reforming reactor 
based on solar radiation, which is similar to present model. Table 1 shows comparison of experimental and simulation results of methane conversion and thermochemical storage efficiency at different conditions. The results show that present numerical model is effective, and methane dry reforming energy storage system can be further analyzed.

\section{Results and Discussions}

\subsection{Heat and Mass Transfer}

Figure 2 shows temperature and main reaction rate distribution of disk reactor. The heat flux distribution of solar simulator conforms to Gaussian distribution, resulting in high energy near the focus which causes high temperature, so the temperature of catalyst bed is a corresponding circular distribution from the center to boundary. Figure 3 shows molar fraction distribution of

Table 1. Simulation and experimental comparison [22].

\begin{tabular}{|c|c|c|c|c|c|c|}
\hline \multirow{2}{*}{$\begin{array}{l}\text { Condition } \\
(y=0.5)\end{array}$} & \multicolumn{3}{|c|}{ Methane conversion (\%) } & \multicolumn{3}{|c|}{$\begin{array}{l}\text { Thermochemical energy storage } \\
\text { efficiency (\%) }\end{array}$} \\
\hline & Experiment & Simulation & $\begin{array}{l}\text { Relative } \\
\text { error }\end{array}$ & Experiment & Simulation & $\begin{array}{c}\text { Relative } \\
\text { error }\end{array}$ \\
\hline $\begin{array}{c}q_{c}=702 \\
\mathrm{~kW} / \mathrm{m}^{2}, \\
F=3 \mathrm{~L} / \mathrm{min}\end{array}$ & 30.9 & 30.0 & -2.90 & 4.02 & 3.69 & 8.15 \\
\hline $\begin{array}{c}q_{c}=714 \\
\mathrm{~kW} / \mathrm{m}^{2} \\
F=4 \mathrm{~L} / \mathrm{min}\end{array}$ & 36.2 & 38.3 & 5.81 & 5.74 & 6.10 & -6.34 \\
\hline $\begin{array}{c}q_{c}=678 \\
\mathrm{~kW} / \mathrm{m}^{2}, \\
F=6 \mathrm{~L} / \mathrm{min}\end{array}$ & 40.5 & 43.5 & 7.29 & 10.1 & 10.9 & -7.66 \\
\hline
\end{tabular}

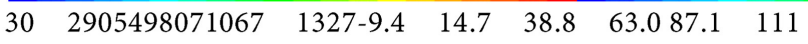

$\left({ }^{\circ} \mathrm{C}\right)\left(\mathrm{mol} / \mathrm{m}^{3} \mathrm{~s}\right)$

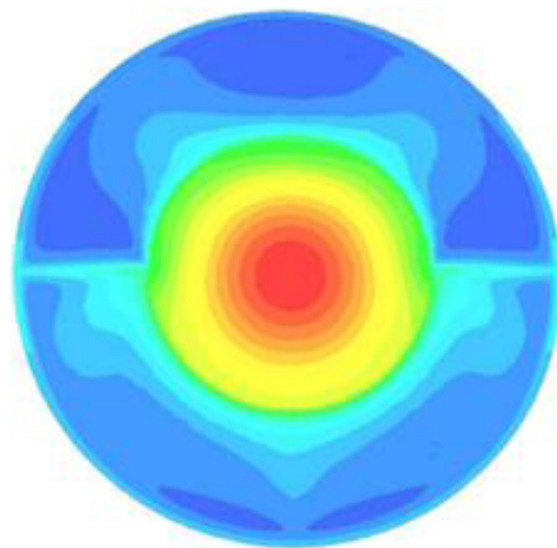

(a) Temperature

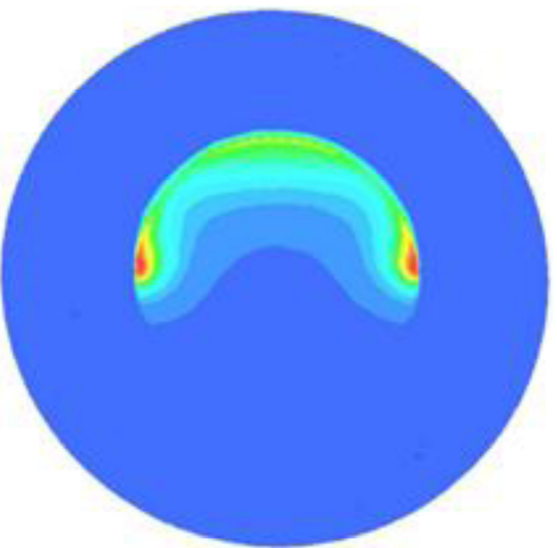

(b) Main reaction rate

Figure 2. Cloud map of temperature and main reaction in heated surface $\left(q_{c}=478\right.$ $\left.\mathrm{kW} / \mathrm{m}^{2}, y=0.5, F=3 \mathrm{~L} / \mathrm{min}\right)$. 


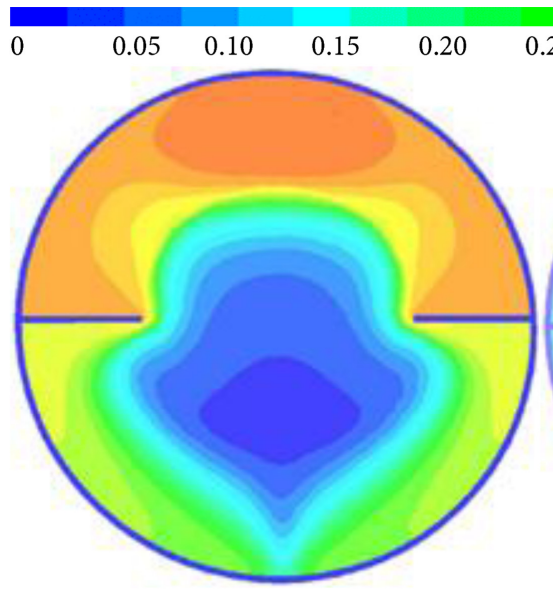

(a) $\mathrm{CH}_{4}$

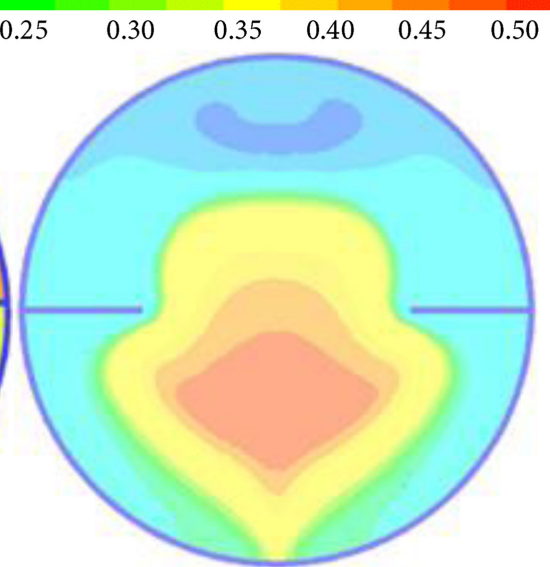

(b) $\mathrm{H}_{2}$

Figure 3. Cloud map of molar fraction $\left(q_{c}=478 \mathrm{~kW} / \mathrm{m}^{2}, y=0.5, F=3 \mathrm{~L} / \mathrm{min}\right)$.

mixed gas. The main reaction rate reaches the maximum value at the corner of the catalyst bed near the baffle and decreases toward the center, because reactant molar fraction as methane increase correspondingly from the center to the boundary, while product molar fraction as hydrogen decrease from the center to the boundary.

Figure 4 shows parameter change in radial direction of catalyst bed. In top boundary of catalyst bed, the temperature corresponds to the distribution of incident energy flux, which gradually decreases from center to boundary. The main reaction rate first increases and then decreases in radial direction, and reaches a maximum value at the corner of catalyst bed baffle of $x=38.7 \mathrm{~mm}$ for the accumulation of reactants near the corners of catalyst bed baffle.

\subsection{Effect of Reactant Flow}

Figure 5 describes the changes of methane conversion and thermochemical storage efficiency with reactant flow in disk reactor system. As the reactant flow increases, catalyst bed temperature and mixed gas outlet temperature decrease, and conversion of methane and carbon dioxide both are reduced, while the thermochemical energy storage efficiency increases. Figure 6 describes the energy ratio of disk reactor as a function of reactant flow. As reactant flow increases, although the mixture gas outlet temperature decreases slightly, the sensible heat storage efficiency increases due to the increase in the total gas volume. The heat loss is reduced for wall temperature decreasing, so the total energy storage efficiency increases.

\subsection{Effect of Reactant Mole Fraction}

Figure 7 presents methane conversion and storage efficiency in disk reactor with different methane molar ratio. As methane molar ratio of reactants increases, methane conversion gradually decreases. The thermochemical energy storage efficiency and total energy storage efficiency increase first and then decrease as 


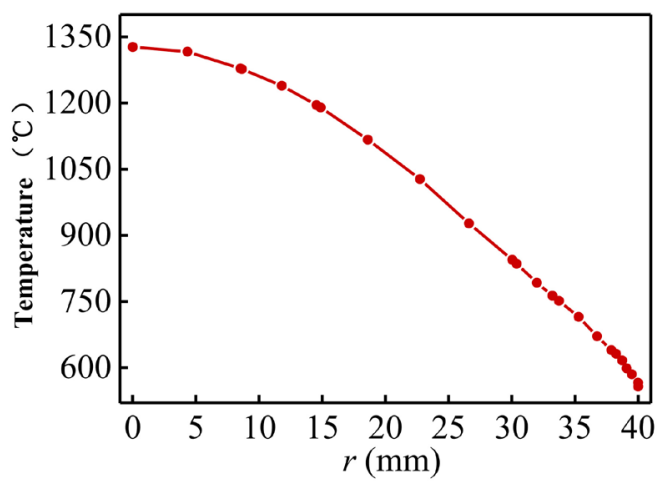

(a)

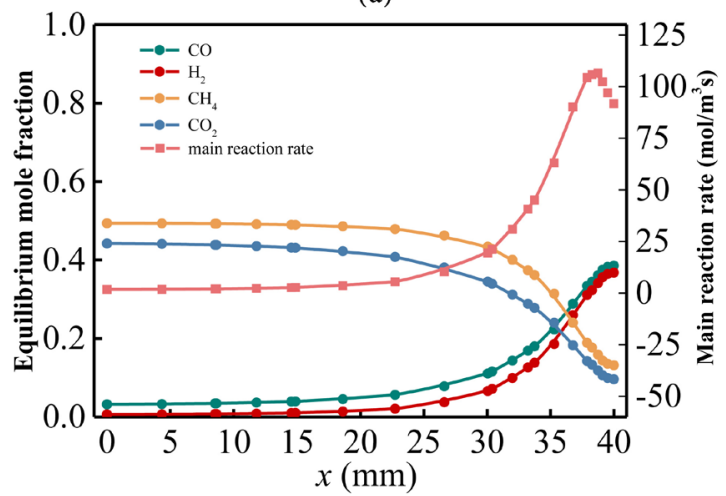

(b)

Figure 4. Parameter change in radial direction of catalyst bed $\left(q_{c}=478 \mathrm{~kW} / \mathrm{m}^{2}, y=0.5, F=3 \mathrm{~L} / \mathrm{min}\right.$ ). (a) Temperature, (b) Molar fraction and main reaction rate.

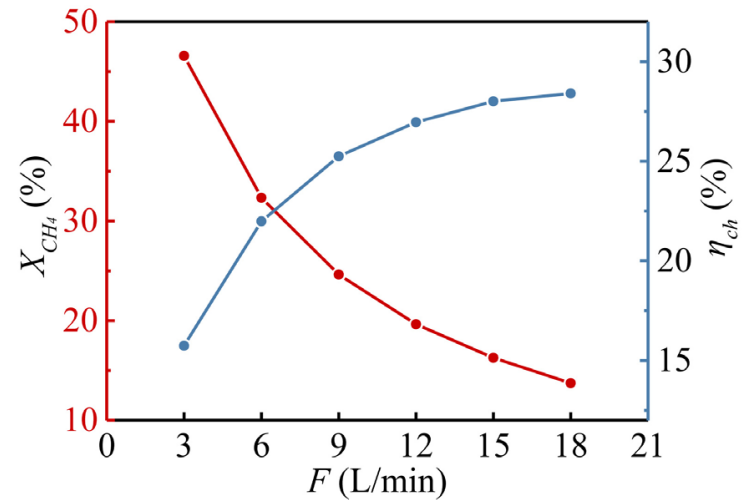

Figure 5. Methane conversion and thermochemical energy storage efficiency in disk reactor with different reactant flow ( $\left.q_{c}=478 \mathrm{~kW} / \mathrm{m}^{2}, y=0.5\right)$.

methane molar ratio increases, reaching a maximum value at $y=0.5$, which is due to the best chemical reaction rate under the ideal molar ratio.

Figure 8 presents molar fraction in disk reactor. Increasing the proportion of carbon dioxide can promote the reverse reaction of water vapor shift reaction. As methane molar ratio of reactants increases, the amount of carbon dioxide gradually decreases, which reduces the likelihood of the reverse reaction of the 


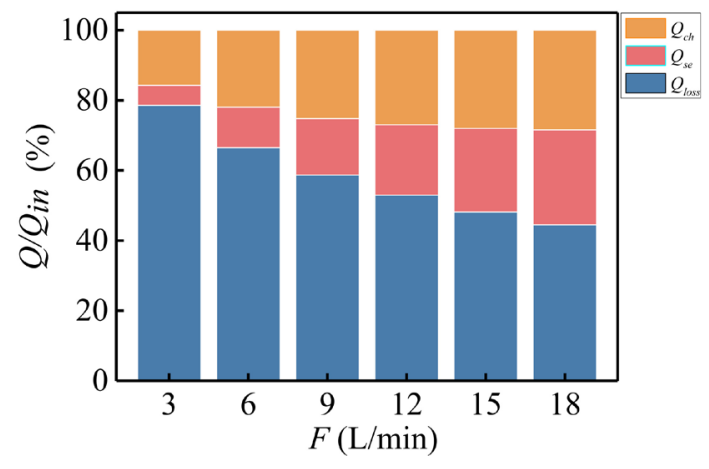

Figure 6. Energy ratio of disk reactor with different reactant flow $\left(q_{c}=478 \mathrm{~kW} / \mathrm{m}^{2}, y=0.5\right)$.

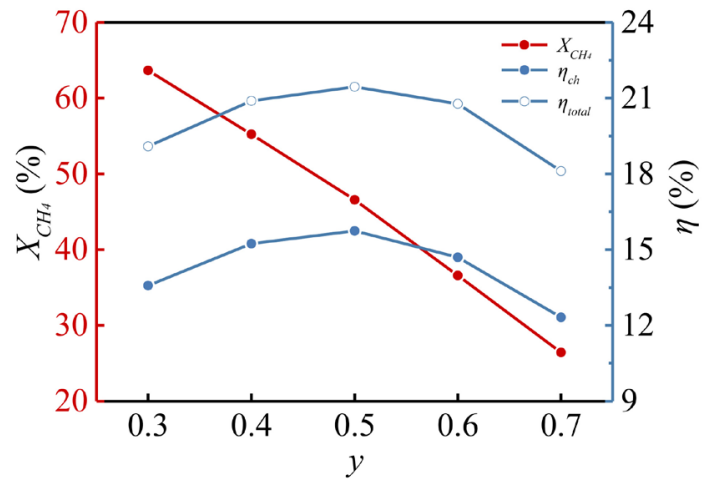

Figure 7. Methane conversion and storage efficiency with different methane molar ratio in disk reactor $\left(q_{c}=\right.$ $\left.478 \mathrm{~kW} / \mathrm{m}^{2}, F=3 \mathrm{~L} / \mathrm{min}\right)$.

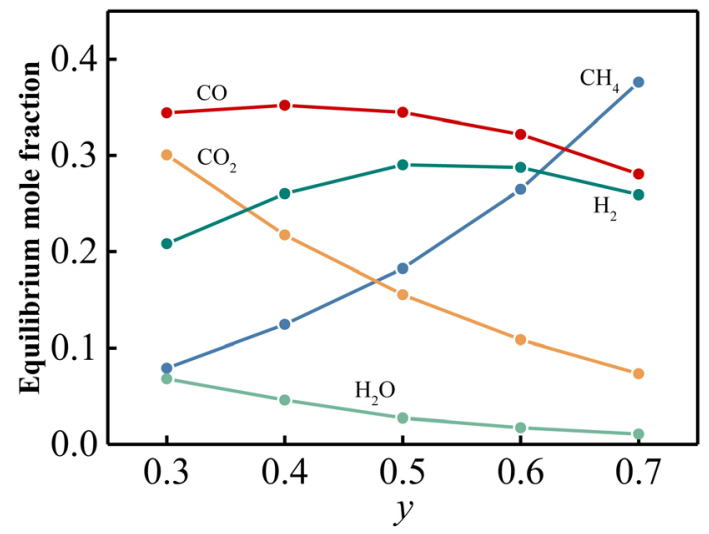

Figure 8. Molar fraction in disk reactor with different methane molar ratio $\left(q_{c}=478 \mathrm{~kW} / \mathrm{m}^{2}, F=3 \mathrm{~L} / \mathrm{min}\right)$.

water vapor shift reaction going forward, thus the amount of by-product $\mathrm{H}_{2} \mathrm{O}$ produced will decrease. On the other hand, the production of $\mathrm{H}_{2}$ gets the maximum at $y=0.5$ under the ideal molar ratio.

\subsection{Effect of Reactant Temperature}

Figure 9 describes methane conversion and energy storage efficiency in disk 


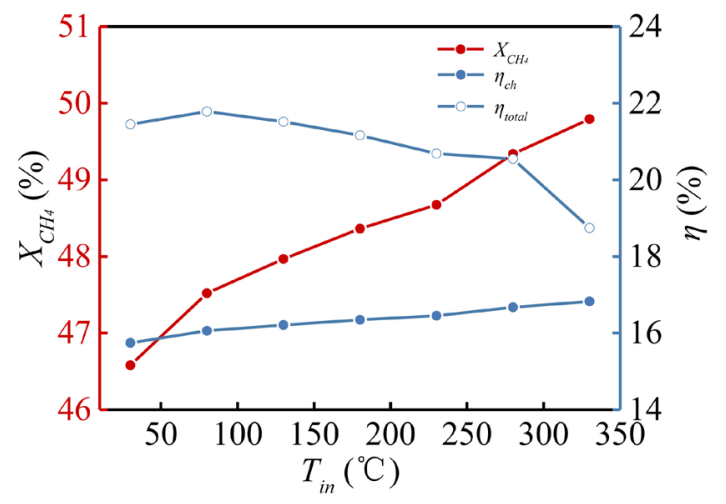

Figure 9. Simulation diagram of methane conversion and energy storage efficiency with reactant temperature in a disk reactor system $\left(q_{c}=478 \mathrm{~kW} / \mathrm{m}^{2}, y=0.5\right.$, $F=3 \mathrm{~L} / \mathrm{min})$.

reactor with different reactant temperature. As reactant temperature rises, methane conversion increases, because inside catalyst bed temperature increases, and then the reaction rate and methane conversion increase accordingly. Since the catalyst bed temperature in reactor does not increase significantly with the increase of reactant temperature, the sensible energy storage decreases significantly. Therefore, the thermochemical energy storage efficiency increases, and the total energy storage efficiency increases slightly and then gradually decreases, as shown in Figure 10.

\subsection{Effect of Catalyst Bed Porosity}

The porosity of catalyst bed has important effect on heat and mass transfer process inside the reactor. Figure 11 describes methane conversion and thermochemical energy storage efficiency in disk reactor with different catalyst bed porosity. The methane conversion and thermochemical energy storage efficiency both increase first and then decrease with the increase of catalyst bed porosity, and the optimal porosity is 0.31 .

\section{Conclusions}

In this paper, heat transfer and energy storage performance of methane carbon dioxide disk reactor with concentrated heat flux were numerically studied, and conclusions are as follows:

1) The thermochemical energy storage efficiency of disk reactor can reach $28.4 \%$, and that is remarkably higher than that of traditional tube reactor.

2) The maximum reaction rate occurs at catalyst bed corner near the baffle, because catalyst bed corner has high temperature and high reactant molar fraction.

3) The trends of methane conversion and thermochemical energy storage efficiency are similar. As the reactant flow increases, methane conversion and thermochemical energy storage efficiency decrease as catalyst bed temperature 


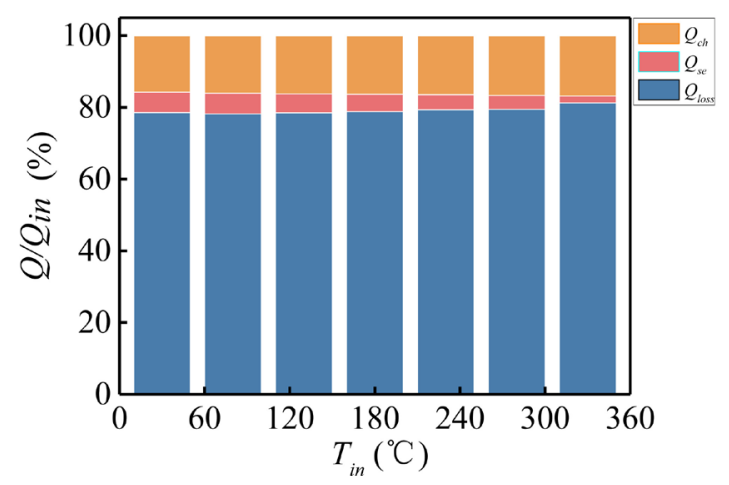

Figure 10. Simulation diagram of energy ratio of disk reactor with reactant temperature $\left(q_{c}=478 \mathrm{~kW} / \mathrm{m}^{2}, y=\right.$ $0.5, F=3 \mathrm{~L} / \mathrm{min})$.

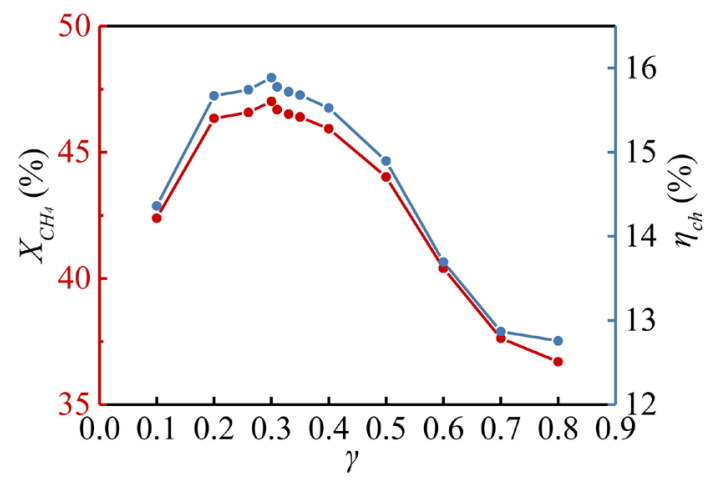

Figure 11. Methane conversion and thermochemical energy storage efficiency in disk reactor with catalyst bed porosity ( $q_{c}=478 \mathrm{~kW} / \mathrm{m}^{2}, y=0.5, F=3 \mathrm{~L} / \mathrm{min}$ ).

and heat loss decrease.

4) Increasing reactant temperature is conducive to improving methane conversion and thermochemical energy storage efficiency.

5) As catalyst bed porosity increases, methane conversion and thermochemical storage efficiency increase first and then decrease, and optimum porosity is 0.31 .

\section{Acknowledgements}

This paper is supported by Natural Science Foundation of Guangdong Province (2017B030308004) and National Natural Science Foundation of China (U1601215, 51961165101).

\section{Conflicts of Interest}

The authors declare no conflicts of interest regarding the publication of this paper.

\section{References}

[1] Dai, L., Long, X.F., Lou, B., Zhou, S.Q. and Xu, Y. (2018) Progress in Thermochem- 
ical Energy Storage for Concentrated Solar Power: A Review. International Journal of Energy Research, 42, 4546-4561. https://doi.org/10.1002/er.4183

[2] Wang, X.H., Du, X.C. and Wei, J.J. (2017) Research Progress of Different Solar Thermochemical Energy Storage Systems. Chinese Science Bulletin, 62, 3631-3642. https://doi.org/10.1360/N972017-00398

[3] Spiewak, I., Tyner, C.E. and Langnickel, U. (1993) Applications of Solar Reforming Technology. https://doi.org/10.2172/10131314

[4] Manfred, B., Ulrich, L. and Manuel, S. (1991) Solar Steam Reforming of Methane. Solar Energy Materials, 43, 441-448. https://doi.org/10.1016/0165-1633(91)90081-U

[5] Böhmer, M., Langnickel, U. and Sanchez, M. (1991) Solar Steam Reforming of Methane. Solar Energy Materials, 24, 441-448. https://doi.org/10.1016/0165-1633(91)90081-U

[6] Buck, R., Muir, J.F. and Hogan, R.E. (1991) Carbon Dioxide Reforming of Methane in a Solar Volumetric Receiver/Reactor: The CAESAR Project. Solar Energy Materials, 24, 449-463. https://doi.org/10.1016/0165-1633(91)90082-V

[7] Muir, J.F., Hogan Jr., R.E., Skocypec, R.D. and Buck, R. (1991) Solar Reforming of Methane in a Direct Absorption Catalytic Reactor on a Parabolic Dish: I-Test and Analysis. Solar Energy, 52, 467-477. https://doi.org/10.1016/0038-092X(94)90654-8

[8] Spiewak, I., Epstein, M. and Segal, A. (1991) The Weizmann Institute of Science 480-kW Reformer System. IEA SSPS Task V. Proceedings of the Workshop on Methane Reforming, Koeln, 11-13 June 1991, 129-137.

[9] Jin, J., Wei, X., Liu, M.K., Yu, Y.H., Li, W.J., Kong, H. and Hao, Y. (2018) A Solar Methane Reforming Reactor Design with Enhanced Efficiency. Applied Energy, 226, 797-807. https://doi.org/10.1016/j.apenergy.2018.04.098

[10] Rubin, R., Karni, J. and Yeheskel, J. (2004) Chemical Kinetics Simulation of High Temperature Hydrocarbons Reforming in a Solar Reactor. Journal of Solar Energy Engineering, 126, 858-866. https://doi.org/10.1115/1.1691439

[11] Akpan, E., Sun, Y., Kumar, P., et al. (2007) Kinetics, Experimental and Reactor Modeling Studies of the Carbon Dioxide Reforming of Methane (CDRM) over a New Ni/CeO $-\mathrm{ZrO}_{2}$ Catalyst in a Packed Bed Tubular Reactor. Chemical Engineering Science, 62, 4012-4024. https://doi.org/10.1016/j.ces.2007.04.044

[12] Akbari, M.H., Ardakani, A.H. and Tadbir, M.A. (2011) A Microreactor Modeling, Analysis and Optimization for Methane Autothermal Reforming in Fuel Cell Applications. Chemical Engineering Journal, 166, 1116-1125.

https://doi.org/10.1016/j.cej.2010.12.044

[13] Wang, F.Q., Shuai, Y., Wang, Z.Q., Leng, Y. and Tan, H.P. (2014) Thermal and Chemical Reaction Performance Analyses of Steam Methane Reforming in Porous Media Solar Thermochemical Reactor. International Journal of Hydrogen Energy, 39, 718-730. https://doi.org/10.1016/j.ijhydene.2013.10.132

[14] Wang, F.Q., Tan, J.Y., Shuai, Y., Gong, L. and Tan, H.P. (2014) Numerical Analysis of Hydrogen Production via Methane Steam Reforming in Porous Media Solar Thermochemical Reactor Using Concentrated Solar Irradiation as Heat Source. Energy Conversion and Management, 87, 956-964. https://doi.org/10.1016/j.enconman.2014.08.003

[15] Wang, F.Q., Tan, J.Y., Ma, L.X. and Leng, Y. (2015) Effects of Key Factors on Solar Aided Methane Steam Reforming in Porous Medium Thermochemical Reactor. Energy Conversion and Management, 103, 419-430. https://doi.org/10.1016/j.enconman.2015.06.049 
[16] Gu, R., Ding, J., Wang, Y.R., et al. (2019) Heat Transfer and Storage Performance of Steam Methane Reforming in Tubular Reactor with Focused Solar Simulator. Applied Energy, 233, 789-801. https://doi.org/10.1016/j.apenergy.2018.10.072

[17] Fernando, A.A.S., Kenia, C.M. and Jornandes, D.S. (2016) A Simulation Study of the Steam Reforming of Methane in a Fixed-Bed Reactor. Engineering, 8, 245-256. https://doi.org/10.4236/eng.2016.84021

[18] Benguerba, Y., Dehimi, L., Virinie, M., Dumas, C. and Ernst, B. (2015) Modelling of Methane Dry Reforming over $\mathrm{Ni} / \mathrm{Al}_{2} \mathrm{O}_{3}$ Catalyst in a Fixed-Bed Catalytic Reactor. Reaction Kinetics Mechanisms and Catalysis, 114, 109-119.

https://link.springer.com/article/10.1007/s11144-014-0772-5

[19] Fluent 6.3 Documentation. http://www.fluent.com

[20] Ergun, S. (1952) Fluid Flow through Packed Columns. Chemical Engineering Progress, 48, 89-94.

[21] Alazmi, B. and Vafai, K. (2000) Analysis of Variants within the Porous Media Transport Models. Journal of Heat Transfer, 122, 303-326. https://doi.org/10.1115/1.521468

[22] Yu, T., Yuan, Q.Q., Lu, J.F., Ding, J. and Lu, Y.L. (2017) Thermochemical Storage Performances of Methane Reforming with Carbon Dioxide in Tubular and Semi-Cavity Reactors Heated by a Solar Dish System. Applied Energy, 185, 1994-2004. https://doi.org/10.1016/j.apenergy.2015.10.131 